\title{
Triage at the Emergency Department: association between triage levels and patient outcome
}

\author{
Triagem no serviço de emergência: associação entre as \\ suas categorias e os desfechos do paciente \\ Cribado en el servicio de emergencia: asociación entre \\ sus categorías y los resultados del paciente
}

Juliana Barros Becker ${ }^{1}$, Maria Carolina Barbosa Teixeira Lopes ${ }^{2}$, Meiry Fernanda Pinto ${ }^{2}$, Cassia Regina Vancini Campanharo $^{2}$, Dulce Aparecida Barbosa ${ }^{2}$, Ruth Ester Assayag Batista ${ }^{2}$

${ }^{1}$ Universidade Federal de São Paulo, Hospital Universitário, São Paulo, SP, Brazil.

${ }^{2}$ Universidade Federal de São Paulo, Escola Paulista de Enfermagem, São Paulo, SP, Brazil.

\section{ABSTRACT}

Objective: Identify association between sociodemographic, clinical and triage categories with protocol outcomes developed at Hospital São Paulo (HSP). Method: Retrospective cohort study conducted with patients older than 18 years submitted to the triage protocol in August 2012. Logistic regression was used to associate the risk categories to outcomes ( $p$-value $\leq 0,05)$. Results: Men with older age and those treated in clinical specialties had higher rates of hospitalization and death. Patients in the high-priority group had hospitalization and mortality rates five and 10.6 times, respectively $(p<0.0001)$. Conclusion: The high-priority group experienced higher hospitalization and mortality rates. The protocol was able to detect patients with more urgent conditions and to identify risk factors for hospitalization and death.

\section{DESCRIPTORS}

Triage; Emergency Medical Service; Emergency Nursing; Protocols.
Corresponding author:

Dulce Aparecida Barbosa

Rua Napoleão de Barros, 754 - Vila Clementino

CEP 04024-002 - São Paulo, SP, Brasil

dulce.barbosa@unifesp.br
Received: 01/19/2015

Approved: 07/09/2015 


\section{INTRODUCTION}

The increasing number of patients seeking Emergency Departments (ED) in recent decades and the consequent overcrowding of ED is a global reality. In developing countries, including Brazil, this problem becomes even more serious because emergency services represent the main access route to the health care system ${ }^{(1-3)}$. Previous studies have shown that overcrowding leads to increased health costs, decreased efficiency and quality of care, and increased incidence of adverse events and mortality, all of which culminate in poor performance of the health care system ${ }^{(4-7)}$.

To prioritize health care for severely ill patients, hospitals have instituted triage systems in recent decades with the aim of identifying patients with more severe conditions and with increased risk of death, thereby ensuring faster service with minimal waiting time ${ }^{(1,8-12)}$. Several protocols and scores are available to triage patients using different levels of severity, but the use of protocols that stratify risk in five levels is recommended because of their increased validity and reliability in assessing the clinical conditions of the patient ${ }^{(2,12,13)}$.

In Brazil, the Ministry of Health published Ordinance No. 2048/2002, which recommends the implementation of patient triage in $\mathrm{ED}{ }^{(14)}$. With the goal of improving care and adapting to current legislation, the University Hospital of the Universidade Federal de São Paulo (UNIFESP) has developed and implemented a protocol that uses a classification system containing five levels of clinical severity defined according to the patient's main complaint. Each level is assigned a color and indicates a maximum estimated waiting time for the provision of emergency care. We chose to develop an exclusive protocol, using the expertise of the hospital staff, because only a few international protocols are available in the Portuguese language, and other protocols require the purchase of expensive software programs ${ }^{(14)}$. In addition, there is the recommendation of the Ministry of Health that the protocol is constructed from the existing literature, however, adapted to the service profile and the context of its inclusion in the health network ${ }^{(15)}$.

Although these triage strategies ensure priority health care for severely ill patients at ED, impacting the quality of care provided to the user ${ }^{(16)}$, few studies have correlated the severity levels established by this classification system and clinical outcomes such as hospital discharge, length of hospitalization, and risk of death ${ }^{(10,17)}$. The correlation between the triage levels and clinical outcomes is important for assessing whether the protocol used ensures patient safety and provides the appropriate allocation of resources and aftercare to decrease hospital costs.

Therefore, this study aimed to identify association between demographic variables, medical specialty and triage protocol categories with outcomes: hospital discharge, hospitalization and death of the protocol developed at Hospital São Paulo (HSP).

\section{METHOD}

This restropective cohort study was conducted in the ED of the Hospital São Paulo (HSP), which is a highly complex university institution that provides emergency care to 700 patients daily, on average. The population served by the ED services mainly consists of adult patients who receive assistance through the Unified Health System (Sistema Único de Saúde - SUS). The study was conducted after approval by the Research Ethics Committee of UNIFESP, protocol 9798, and followed in accordance with all ethical standards required.

The ED triage at the HSP is performed by trained nurses using an institutional protocol developed and implemented in 2009 by doctors and nurses of the institution, based on the literature on the topic and expertise of those involved. Since the beginning of its use, this is the first study designed to evaluate it in relation to the quality of its rating. The initial training was conducted through lecture protocol for $\mathrm{SE}$ nurses. The protocol, created on the basis of the main patient complaint, allows the medical team to determine the priority of care through assessment of the patient's signs and symptoms. The level of risk was stratified using five levels of clinical severity, and a color was assigned to each level. Each color represents a level of severity and the maximum waiting time allowed for the provision of health care. The red color indicates emergency care, and medical assistance should be provided immediately; the orange color indicates very urgent cases, and the waiting time recommended is no more than 15 minutes; the yellow color indicates urgent cases, and the waiting time recommended is 60 minutes; the green color indicates little urgency and the blue color no urgency, and the waiting time allowed in these conditions is two and four hours, respectively.

During triage, a nursing consultation is performed to evaluate the complaint, at which time the vital signs are measured, and patients are asked about signs and symptoms, onset of the condition, personal history, current drug therapies, and allergies. Each case is assigned a color, and the patient is referred to either clinical specialties (internal medicine, neurology, and psychiatry) or surgical specialties (general surgery, gynecology, neurosurgery, otolaryngology, and orthopedics). These data are recorded in medical records and stored in the institution's information system.

In this study, the following variables were recorded: age, gender, time of arrival at the ED, medical specialty, and a color corresponding to the level of priority was assigned. Data were collected retrospectively from electronic medical records of all patients older than 18 years who received medical care during ED triage in August 2012. The outcomes evaluated were hospital discharge, length of hospitalization, and death.

Data were analyzed using SPSS software version 19. Sample size was calculated based on the intersection between the color of risk classification and outcome (hospital discharge, death and hospitalization) by the Likelihood Ratio (likelihood ratio $=39.745$, $\mathrm{p}$ value $=0.0040$ ) consider- 
ing a significance level of $5 \%$ and power of $80 \%$ for 84 patients. Because of the small size of the deceased group, which would compromise the results of the statistical tests, random data collection was extended until five patients were obtained in this group, as a consequence the sample totaled 3956 patients.

For data analysis, medical specialties were divided into clinical and surgical specialties. In addition, the five triage levels were grouped, based on international article that held similar division, using Manchester protocol ${ }^{(9)}$ , into high priority (red - emergency and orange - very urgent ) and low priority (yellow - urgent, green - some urgent and blue - not urgent ).

In the low- and high-priority groups, the triage levels, gender, age, and medical specialty were compared with the outcomes (hospital discharge, length of hospitalization, and death) using the Chi-square Test as well as the Likelihood Ratio when necessary. Analysis of variance (ANOVA) was used to compare patient age with outcome, triage level, and medical specialty; for the significant results, the Bonferroni correction was used for multiple comparisons. To analyze the factors that have strongest correlation with patient outcome were used
Logistic Regression Multinomial Simple to verify the relationship of each independent variable (age, gender, medical specialties and triage levels) in relation to the dependent variable (outcome). Subsequently, the stepwise method was used to select the set of independent variables that best explain the outcome of patient, through Logistic Regression Multinomial Multiple. All variables of the simple model were selected for the multivariate model. The hospital discharge outcome was used as the reference category. A significance level of $5 \%(\mathrm{p} \leq 0.05)$ was adopted.

\section{RESULTS}

Most patients were classified as low priority (89.7\%) during ED triage in the following proportions: $15.9 \%$ yellow, green $56.5 \%, 17.2 \%$ blue. Conversely, patients classified as high priority $10.3 \%$ of total demand $(4.2 \%$ red and orange $6.2 \%$ ). Patients classified as high priority accounted for $11.80 \%$ of the consultations during the daytime period (06:05 am-6:00 pm) and for 13.60\% of the consultations during the nighttime period (06:05 pm-06:00 am). The mortality rate was higher in the high-priority group (3.2\%) (Table 1).

Table 1 - Demographics, medical specialty, arrival time and outcomes of patients submitted to triage protocol in the Emergency Department - São Paulo-SP, Brazil, 2012.

\begin{tabular}{|c|c|c|}
\hline Demographic and population data & $\begin{array}{l}\text { High Priority* } \\
n=409\end{array}$ & $\begin{array}{c}\text { Low Priority** } \\
\mathrm{n}=3547\end{array}$ \\
\hline \multicolumn{3}{|l|}{ Age } \\
\hline Mean (SD) & $46,9(20,1)$ & $44,3(17,5)$ \\
\hline \multicolumn{3}{|l|}{$\operatorname{Sex}(\%)$} \\
\hline Male & $166(40,6)$ & $1419(40)$ \\
\hline Female & $243(59,4)$ & $2128(60)$ \\
\hline \multicolumn{3}{|l|}{ Specialties (\%) } \\
\hline Clinical & $224(14,6)$ & $1314(85,4)$ \\
\hline Surgical & $185(7,6)$ & $2233(92,4)$ \\
\hline \multicolumn{3}{|l|}{ Time $(\%) * * *$} \\
\hline $6: 00$ am to $5: 55 p m$ & $276(11,8)$ & $2071(88,2)$ \\
\hline 6:00pm to $5: 55 \mathrm{am}$ & $133(13,6)$ & $846(86,4)$ \\
\hline \multicolumn{3}{|l|}{ Outcome (\%) } \\
\hline Discharge & $324(79,2)$ & $3414(96,3)$ \\
\hline Hospital Admission & $72(17,6)$ & $124(3,5)$ \\
\hline Death & $13(3,2)$ & $9(0,3)$ \\
\hline
\end{tabular}

* High priority - red and orange colors; ** Low priority - yellow, green and blue; ***Arrival time in ED.

Table 2 shows that the average age in the deceased group was 1.23 and 1.43 times higher than in the hospitalized and discharged groups, respectively. Moreover, the average age in the hospitalized group was 1.15 times higher than in the discharged group (ANOVA $\mathrm{F}=26.87 ; \mathrm{p}<0.0001$ ). Men had higher hospitalization and mortality rates than women $\left(\chi^{2}=13: 58 ; \mathrm{p}=0.0011\right)$. 
Table 2 - Variables associated with the outcomes of patients submitted to triage protocol in the Emergency Department - São PauloSP, Brazil, 2012.

\begin{tabular}{|c|c|c|c|c|c|}
\hline & & Outcome & & & \\
\hline & Discharge & $\begin{array}{l}\text { Hospital } \\
\text { Admission }\end{array}$ & Death & & \\
\hline Age & & & & & \\
\hline Mean (SD) & $44,09(17,7)$ & $51,12(18,3)$ & $63,18(16,2)$ & $44,55(17,8)$ & $<0,0001^{* * *}$ \\
\hline Sex $(\%)$ & & & & & \\
\hline Male & $1475(93,1)$ & $95(6,0)$ & $15(0,9)$ & 1585 (100) & $0,0011^{* * * *}$ \\
\hline Female & $2263(95,4)$ & $101(4,3)$ & $7(0,3)$ & $2371(100)$ & \\
\hline Specialties (\%) & & & & & \\
\hline Clinical & $1433(93,2)$ & $87(5,6)$ & $18(1,2)$ & 1538 (100) & $<0,0001 * * * *$ \\
\hline Surgical & $2305(95,3)$ & $109(4,5)$ & $4(0,2 \%)$ & $2418(100)$ & \\
\hline Triage categori & & & & & \\
\hline High- priority & $324(79,2)$ & $72(17,6)$ & $13(3,2)$ & $409(100)$ & $<0,0001^{* * * *}$ \\
\hline Low -priority & $3414(96,3)$ & $124(3,5)$ & $9(0,3)$ & 3547 (100) & \\
\hline
\end{tabular}

*Clinical specialties: general medicine, neurology, psychiatry; Surgical specialties: general surgery, gynecology, neurosurgery, otolaryngology, orthopedics; ${ }^{* *}$ High Priority - red and orange colors; Low priority - yellow, green and blue. **** Analysis of Variance (ANOVA) ***** chi-square test. Note ( $\mathrm{n}=3956)$.

Significant differences were observed between the highand low-priority groups; the rate of hospitalization in the high-priority group was 5-fold higher, and the mortality rate was 10.6 times higher than in the low-priority group $\left(\chi^{2}=214.99, \mathrm{p}<0.0001\right)$.

The analysis of the medical specialties indicated that the average age of patients referred to clinical specialties was significantly higher than the average age of patients referred to surgical specialties (ANOVA F=60.30; $p<0.0001$ ). The highpriority group consisted predominantly of clinical patients $\left(\chi^{2}=48.47 ; \mathrm{p}<0.0001\right)$, and this group experienced higher hospitalization and mortality rates $\left(\chi^{2}=20.04 ; p<0.0001\right)$ and longer periods of hospitalization (ANOVA F $=13.0 ; \mathrm{p}=0.0004$ ) compared with surgical patients. The length of hospitalization among the surgical patients was 1.98 times higher and the mortality rate was 6 -fold higher than the values obtained in clinical patients.

The variable age is strongly associated with outcomes hospitalization and death ( $<<0.0001$; OR 1.02 and 1.05), ie, the higher the age, the more likely to be hospitalized or go to death. The same happened with the variable gender, where results showed that males have greater risk of hospitalization $(\mathrm{p}=$ $0.0144 ; \mathrm{OR}=1.45)$ and deaths $(\mathrm{p}=0.0177 ; \mathrm{OR}=3.03)$. The association of medical specialties with the outcomes showed that patients treated in clinical specialties at higher risk of death than those treated in surgical specialties $(\mathrm{p}=0.0282$; $\mathrm{OR}=3.56)($ Table 3$)$.

The odds ratio (OR) between age and medical specialties in the two priority groups indicated that the likelihood of being classified in the high-priority group increased by $1 \%$ per year of age $(p=0.0037, O R=1.01)$. The likelihood of clinical patients being classified as high priority was 2.06 times higher than for surgical patients ( $\mathrm{p}<0.0001, \mathrm{OR}=2.06$ ).

By contrast, the odds ratio of the different outcomes in both priority groups indicated that the likelihood of hospitalization was 6,05 times higher $(p<0.0001, O R=6,05)$ and the likelihood of death was 9,41 times higher among high-priority patients than low-priority patients $(\mathrm{p}<0.0001, \mathrm{OR}=9,41)$.

Table 3 - Results of the multiple regression multinomial logistic analysis, having as dependent variable the outcome hospital discharge - São Paulo, Brazil 2012.

\begin{tabular}{|c|c|c|c|}
\hline Variables & Outcomes & OR* & p-value \\
\hline Age & Hospital Admission & 1,02 & $<0,0001$ \\
\hline Gender ** (Male x Female) & & 1,45 & 0,0144 \\
\hline Specialties $* * *$ (Clinical x Surgical) & & 0,90 & 0,5097 \\
\hline Triage Categories**** (High x Low-priority) & & 6,05 & $<0,0001$ \\
\hline Age & Death & 1,05 & 0,0003 \\
\hline Gender ** (Male x Female) & & 3,03 & 0,0177 \\
\hline Specialties $* * *$ (Clinical $\times$ Surgical) & & 3,56 & 0,0282 \\
\hline Triage Categories**** (High $\mathrm{x}$ Low-priority) & & 9,41 & $<0,0001$ \\
\hline
\end{tabular}

*OR - odds ratio; ${ }^{* *}$ reference category: female; ${ }^{* * * *}$ reference : Surgical specialties; ***** reference: low-priority. 


\section{DISCUSSION}

The results of this study are consistent with previously reported data. The study population consisted predominantly of women $(59,9 \%)$ with a mean age of 45,6 years, with a larger number of low-complexity consultations $(89,7 \%)$ performed during the day $(75,3 \%)^{(1,18-20)}$.

The classification protocol evaluated has five levels of clinical severity and is considered the gold standard of classification systems ${ }^{(2,12)}$. As one of the goals of the triage system in the ED is to correctly and systematically assess the severity of illness of patients ${ }^{(2)}$, the protocol evaluated showed consistency because the hospitalization and mortality rates were five and 10,6 times higher in the high-priority group, respectively, compared with the low-priority group. Two European studies using the Manchester Triage System (MTS) and the Emergency Severity Index (ESI) obtained similar results ${ }^{(9,17)}$. One can also say that the protocol could predict early mortality, ie , that occurred within 48 hours of hospitalization, since $85.7 \%$ of these deaths occurred in patients classified in the priority group.

Discharged patients accounted for $94.5 \%$ of the consultations during $\mathrm{ED}$ triage. Of these discharged patients, 91.3\% were classified as low priority. These findings indicate the inadequate use of emergency services, as most patients treated in the ED could be assisted using less complex services. The low efficiency of the primary health care and the precariousness of the hospital network are responsible for patient overcrowding in ED in Brazil ${ }^{(21)}$.

In this study, the hospitalized and deceased patients exhibited higher age than the group of discharged $\mathrm{pa}^{-}$ tients $(p<0.0001)$. In addition, the odd ratios indicated a greater likelihood of patients being classified as high priority as they age as well as increased risk of hospitalization and death. A European study that evaluated the correlation of ED triage (using MTS and ESI) with the hospitalization and mortality rates found similar results, demonstrating that age was a significant predictor of urgency ${ }^{(17)}$. A recent national study evaluated the demand for ED services using the MTS and indicated that older patients were classified into higher levels of clinical severity ${ }^{(22)}$. Other studies have shown an increased risk of death within 30 days after arrival at the ED among older patients ${ }^{(23)}$. These data support the inclusion of age in triage protocols for the assessment of clinical severity.

This study found significant differences between the clinical and surgical specialties. Most patients who received ED care were referred to surgical specialties (61.1\%). However, the high-priority group consisted predominantly of clinical patients, and this group experienced higher hospitalization and mortality rates and longer periods of hospitalization $(p=0.0004)$ than the surgical patients. The odds ratio also showed a higher risk of death in patients treated in clinical specialties. Accordingly, a Portuguese study evaluated hospitalization and mortality rates using the MTS and indicated that most deaths and hospitalizations occurred in the high-priority group and involved predominantly clinical patients ${ }^{(10)}$. According to the report by the Pan American Health Organization published in 2012, seven of the ten leading causes of death in the Americas involve chronic diseases. In Brazil, ischemic heart disease, cerebrovascular disease, and cancer of the digestive system are the three leading causes of death in the adult population ${ }^{(24)}$. As most chronic diseases are treated clinically, the results presented herein indicate that the higher hospitalization and mortality rates among the clinical patients may be correlated with these epidemiological data.

The groups classified as high and low priority corresponded to $10.3 \%$ and $89.7 \%$ of the triaged patients, respectively. These results corroborate the findings of another study in which most patients were classified as low complexity ${ }^{(25)}$. The correlation of the priority groups with the different outcomes indicated that high-priority patients had an increased rate of hospitalization, longer periods of hospitalization, and higher mortality rates. The odds ratio also showed a greater chance of hospitalization and death in patients in the high-priority group. These results corroborate the findings of similar studies using validated international protocols, in which patients classified as severely ill had higher hospitalization and mortality rates ${ }^{(10,17,25)}$.

In the sample studied men and women were homogeneous with respect to age, but the hospitalization and mortality rates in men were higher than in women. This result may be related to the behaviors and life styles of men, who exhibit lower adherence to preventive care and increased exposure to harmful health habits ${ }^{(26-30)}$.

Limitations of this study were performing in a single center and the use of protocol developed locally, which limited the comparison with other studies and that can make it difficult to generalize the results to other populations and regions. However, the results shown herein demonstrate the importance of evaluating institutional protocols that have not been previously validated and suggest that these protocols can serve as models to be replicated.

\section{CONCLUSION}

The five-level protocol evaluated was able to predict different outcomes, since the high-priority group experienced greater hospitalization and mortality rates. The variables age, gender, and clinical specialties were also associated with higher rates of hospitalization and death, since patients with age, men and patients treated in clinical specialties had higher rates of hospitalization and death, especially those classified in the high-priority group.

The results of this study demonstrate that the evaluated protocol, despite lack of validation studies, was able to detect patients with more urgent conditions and to identify higher risk for hospital admission and death, indicating that the development of own protocols, adapted to the profile 
of the patient groups, can be an alternative in the ED to international triage protocols in Health Institutions with limited financial resources.

The strategy adopted in the study is easy to replication and can be a protocol evaluation mechanism other institutions. Obtaining an estimate regarding the outcomes of patients may contribute to the provision of physical resources, human and material, assisting in the management of the institution.

These data demonstrate the importance of triage methods in the ED for the management of potentially severely ill patients, prioritizing the care of these patients with the aim of improving the quality of care and patient safety.

\section{RESUMO}

Objetivo: Identificar a associação entre variáveis sociodemográficas, clínicas e categorias de triagem com desfechos do protocolo desenvolvido no Hospital São Paulo (HSP). Método: Estudo de coorte retrospectivo realizado com pacientes maiores de 18 anos submetidos ao protocolo de triagem em agosto de 2012. Utilizou-se regressão logística para associar as categorias de risco aos desfechos ( $p$-valor $\leq 0,05)$. Resultados: Homens com idade mais avançada e atendidos pelas especialidades clínicas apresentaram maiores taxas de internação e óbito. Pacientes com alta prioridade apresentaram taxa de internação e óbitos cinco e 10,6 vezes maior, respectivamente $(p<0,0001)$. Conclusão: $O$ grupo de maior prioridade associou-se a maiores taxas de internação e óbitos. O protocolo foi capaz de detectar pacientes com condições mais urgentes e identificar fatores de risco para internação hospitalar e óbito.

\section{DESCRITORES}

Triagem; Serviços Médicos de Emergência; Enfermagem em Emergência; Protocolos.

\section{RESUMEN}

Objetivo: Identificar la asociación entre variables sociodemográficas, clínicas y categorías de cribado con resultados del protocolo desarrollado en el Hospital São Paulo (HSP). Método: Estudio de cohorte retrospectivo llevado a cabo con pacientes mayores de 18 años sometidos al protocolo de cribado en agosto de 2012. Se utilizó la regresión logística para asociar las categorías de riesgo a los resultados ( $p$-valor $\leq 0,05$ ). Resultados: Hombres con edad más avanzada y atendidos por las especialidades clínicas presentaron mayores índices de estancia hospitalaria y defunción. Pacientes con alta prioridad presentaron índice de estancia hospitalaria y defunción cinco y 10,6 veces mayor, respectivamente $(\mathrm{p}<0,0001)$. Conclusión: El grupo de mayor prioridad se asoció con mayores índices de estancia hospitalaria y defunciones. El protocolo fue capaz de detectar a pacientes con condiciones más urgentes e identificar factores de riesgo para estancia hospitalaria y defunción.

\section{DESCRIPTORES}

Triaje; Servicios Médicos de Urgencia; Enfermería de Urgencia; Protocolos.

\section{REFERENCES}

1. Duran AC, Gentile S, Gerbeaux P, Alazia M, Kiegel P, Luigi S, et al. Be careful with triage in emergency departments: interobserver agreement on 1,578 patients in France. BMC Emerg Med. 2011; 11:19.

2. Christ M, Grossmann F, Winter D, Bingisser R, Platz E. Modern Triage in the Emergency Department. Dtsch Arztebl Int. 2010;107(50):892-8.

3. Anneveld M, Van der Linden C, Grootendorst D, Galli-Leslie M. Measuring emergency department crowding in an inner city hospital in The Netherlands. Int J Emerg Med. 2013;6(1):21.

4. Fovero R, McCarthy S, Hillman K. Access block and emergency department overcrowding. Crit Care. 2011;15(2):216.

5. Gilligan P, Joseph D, Bartlett M, Morris A, Mahajan A, McHugh K, et al. The 'who are all these people?' study. Emerg Med J. 2015;32(2):10911.

6. Widgren B, Jourak M. Medical emergency triage and treatment system (METTS): a new protocol in primary triage and secondary priority decision in emergency medicine. J Emerg Med. 2011;40(6):623-8.

7. Mahmoodian F, Eqtesadi R, Ghareghani A. Waiting times in emergency department after using the emergency severity index triage tool. Arch Trauma Res. 2014;3(4):e19507.

8. van der Linden C, Lindeboom R, van der Linden N, Lucas C. R. Managing patient flow with triage streaming to identify patients for Dutch emergency nurse practitioners. Int Emerg Nurs. $2012 ; 20(2): 52-7$.

9. Martins HM, Cunã LM, Freitas P. Is Manchester (MTS) more than a triage system? A study of its association with mortality and admission to a large Portuguese hospital. Emerg Med J. 2009;26(3):183-6.

10. Dallaire C, Poitras J, Aubin K, Lavoie A, Moore L. Emergency department triage: do experienced nurses agree on triage scores? J Emerg Med. 2012;42(6): 736-40.

11. Storm-Versloot MN, Vermeulen H, van Lammeren N, Luitse JSK, Goslings JC. Influence of the Manchester triage system on waiting time, treatment time, length of stay and patient satisfaction: a before and after study. Emerg Med J. 2014;31(1):13-8.

12. Storm-Versloot MN, Ubbink DT, Kappelhof J, Luitse JS. Comparison of an informally structured triage system, the Emergency Severity Index, and de Manchester triage system to distinguish patient priority in the emergency department. Acad Emerg Med. 2011;18(8):822-9.

13. Brasil. Ministério da Saúde. Portaria GM/MS n. 2048, de 5 de novembro de 2002. Aprova o Regulamento Técnico dos Sistemas Estaduais de Urgência e Emergência. Diário Oficial da União, Brasília, 12 nov. 2002. Seção 1, p. 32-54. 
14. Souza CC, Toledo AD, Tadeu LFR, Chianca TCM. Risk classification in an emergency room: agreement level, between a Brazilian institutional and the Manchester Protocol. Rev Latino Am Enfermagem. 2011;19(1):26-33.

15. Brasil. Ministério da Saúde. Humaniza SUS - Acolhimento e Classificação de Risco nos Serviços de Urgência. Brasília: MS; 2009.

16. Souza CC, Diniz AS, Silva LL, Mata LRF, Chianca TCM. Nurses' perception about risk classification in emergency services. Invest Educ Enferm. 2014; 32(1):78-86.

17. van der Wulp I, Schrijvers AJP, Stel HFV. Predicting admission and mortality with the Emergency Severity Index and Manchester Triage System: a retrospective observational study. Emer Med J. 2009 Jul; 26(7):506-9.

18. Guedes HM, Almeida AGP, Ferreira FO, Vieira Jr G , Chianca TCM. Classificação de risco: retrato de população atendida num serviço de urgência brasileiro. Rev Enf Ref [Internet]. 2014 [citado 2015 fev. 28]; serIV(1): 37-44. Disponível em: http://dx.doi.org/10.12707/RIII13108

19. Durand AC, Gentile S, Devictor B, Palazzolo S, Vignally P, Gerbeaux P, et al. ED patients: how nonurgent are they? Systematic review of emergency medicine literature. Am J Emerg Med. 2011;29(3):333-45.

20. Sunyoto T, Vander Berg R, Valles P, Gutierrez R, Ayada L, Zachariah R, et al. Providing emergency care and assessing a patient triage system in a referral hospital in Somaliland: a cross-sectional study. BMC Health Serv Res. 2014;14:531.

21. O' Dwyer GO, Oliveira SP, Sete MH. Evaluation of emergency services of the hospitals from the QualiSUS program. Ciên Saúde Coletiva. 2009;14(5):1881-90.

22. Diniz AS, Silva AP, Souza CC, Chianca TCM. Clinical demand in an emergency care unit according to the Manchester triage system. Rev Eletr Enf [Internet]. 2014 [citado 2014 nov. 12];16(2):312-20. Disponível em: http://revistas.ufg.br/index.php/fen/article/view/21700

23. Farrohknia N, Castrén M, Ehrenberg A, Lind L, Oredsson S, Jonsson H, et al. Emergency department triage scales and their components: a systematic review of the scientific evidence. Scand J Trauma Resusc Emerg Med. 2011;19:42.

24. Organização Pan-Americana da Saúde; Organização Mundial da Saúde. Saúde nas Américas. Edição 2012. Washington: OPAS; 2012.

25. Santos P, Freitas P, Martins HM. Manchester triage system version II and resource utilization in emergency department. Emerg Med J. 2014;31(2):148-52.

26. World Health Organization. Noncommunicable diseases country profiles 2011. Geneva: WHO; 2011.

27. Oliveira MM, Daher DV, Silva JL, Andrade SSC. Men's health in question: seeking assistance in primary health care. Ciên Saúde Coletiva. $2015 ; 20(1): 273-78$.

28. World Health Organization. Global status report on noncommunicable diseases 2010. Geneva: WHO; 2011.

29. Alwan A, MacLean DR, Riley LM, d'Espaignet ET, Mathers CD, Stevens GA, et al. Monitoring and surveillance of chronic non-communicable diseases: progress and capacity in high-burden countries. Lancet. 2010;376(9755):1861-8.

30. Luizaga CTM, Gotlieb SLD. Male mortality in three Brazilian State Capitals, 1979-2007. Rev Bras Epidemiol. 2013;16(1):87-99. 